\title{
Suppressing Green Mold Decay in Grapefruit with Postharvest Jasmonate Application
}

\author{
Samir Droby, ${ }^{1}$ Ron Porat, Lea Cohen, Batia Weiss, Boris Shapiro, Sonia Philosoph-Hadas, and \\ Shimon Meir \\ Department of Postharvest Science of Fresh Produce, Agricultural Research Organization, The Volcani \\ Center, Bet Dagan 50250, Israel
}

\begin{abstract}
Additional Index words. chilling injury, Citrus paradisi, green mold, induced resistance, jasmonic acid, methyl jasmonate, Penicillium digitatum

Abstract. Jasmonic acid (JA) and methyl jasmonate (MJ), collectively referred to as jasmonates, are naturally occurring plant growth regulators involved in various aspects of plant development and responses to biotic and abiotic stresses. In this study, we found that postharvest application of jasmonates reduced decay caused by the green mold Penicillium digitatum (Pers.: Fr.) Sacc. after either natural or artificial inoculation of grapefruit (Citrus paradisi 'Marsh Seedless'). These treatments also effectively reduced chilling injury incidence after cold storage. The most effective concentration of jasmonates for reducing decay in cold-stored fruit or after artificial inoculation of wounded fruit at $24{ }^{\circ} \mathrm{C}$ was $10 \mu \mathrm{mol} \cdot \mathrm{L}^{-1}$. Higher and lower jasmonate concentrations were less effective at both temperatures. $\mathrm{MJ}$ at $10 \mu \mathrm{mol} \cdot \mathrm{L}^{-1}$ also most effectively reduced the percentage of fruit displaying chilling injury symptoms after 6 weeks of storage at $2{ }^{\circ} \mathrm{C}$ and 4 additional d at $20^{\circ} \mathrm{C}$. When tested in vitro, neither JA nor MJ had any direct antifungal effect on $P$. digitatum spore germination or germ tube elongation. Therefore, it is suggested that jasmonates probably reduced green mold decay in grapefruit indirectly by enhancing the natural resistance of the fruit to $P$. digitatum at high and low temperatures.
\end{abstract}

Green and blue mold rots of citrus caused by Penicillium digitatum and $P$. italicum Wehmer, respectively, account for most of the postharvest losses of citrus fruit world-wide (Eckert and Brown, 1986). These pathogens are primarily controlled by extensive use of chemical fungicides (Eckert and Ogawa, 1985). Effective suppression of postharvest decay could also be achieved by storing the fruit at low temperatures. In grapefruit, however, storage below the optimal storage temperature $\left(11^{\circ} \mathrm{C}\right)$ results in the appearance of chilling injury (CI) symptoms, expressed as pitting of the fruit peel surface and increased attack by mold pathogens and stem end rots (Chalutz et al., 1981). To overcome this problem, relatively high concentrations of fungicides have been used to control postharvest decay (Schiffman-Nadel et al., 1975). In the search for alternatives to fungicides, several other methods have been employed to reduce CI and its consequent decay in citrus fruit; these include intermittent warming (Cohen, 1988; Wang, 1993), and hot water dips (Rodov et al., 1995). Treatments with methyl jasmonate (MJ) have also been reported to effectively reduce CI in grapefruit (Meir et al., 1996), as well as in other chilling-susceptible commodities (Wang and Buta, 1994; Meir et al., 1996).

Jasmonic acid (JA) and MJ, collectively referred to as jasmonates, are naturally occurring plant growth regulators that are widely distributed in the plant kingdom, and are known to regulate various aspects of plant development and responses to environmental stresses (Creelman and Mullet, 1995, 1997; Sembdner and Parthier, 1993).

In addition, several lines of evidence suggest that jasmonates play an important role as signal molecules in plant defense responses against pathogen attack. First, JA accumulates in plant tissues or in cell cultures treated with elicitors of plant defense mechanisms (Doares et al., 1995; Gundlach et al., 1992; Nojiri et al., 1996). Second, jasmonates have been shown to activate genes

Received for publication 7 July 1998. Accepted for publication 20 Nov. 1998. ARO, The Volcani Center, contribution 413-98. The cost of publishing this paper was defrayed in part by the payment of page charges. Under postal regulations, this paper therefore must be hereby marked advertisement solely to indicate this fact ${ }^{1}$ To whom reprint requests should be addressed; vtsdroby@volcani.agri.gov.il. encoding antifungal proteins such as thionin (Andresen et al., 1992), osmotin (Xu et al., 1994), a novel ribosome-inactivating protein JIP60 (Chaudhry et al., 1994), and several other genes involved in phytoalexin biosynthesis (Creelman et al., 1992; Gundlach et al., 1992).

Moreover, modifying levels of jasmonates by exogenous applications of JA and MJ has effectively protected potato and tomato plants against infection by the late blight Phytophthora infestans (Mont.) de Bary (Cohen et al., 1993), and barley plants against infection by the powdery mildew Erysiphe graminis f. sp. hordei (Schweizer et al., 1993). Recently, it was reported that MJ can also be applied effectively, as a postharvest treatment, to suppress the gray mold rot caused by Botrytis cinerea Pers.: Fr. in strawberries (Moline et al., 1997) and in cut roses (Meir et al., 1998), and to reduce microbial contamination in celery and peppers (Buta and Moline, 1998).

The aim of the present study was to examine further the possible applications of JA and MJ as alternative postharvest treatments to reduce decay in citrus fruit. MJ dipping has been previously demonstrated to markedly reduce CI incidence in 'Marsh Seedless' grapefruit, after cold storage (Meir et al., 1996). Therefore, we chose this citrus fruit as a model system, to examine the effects of jasmonates on the development of green mold decay, after either natural or artificial infection with $P$. digitatum.

\section{Materials and Methods}

Plant material and fungal cultures. Grapefruit (Citrus paradisi 'Marsh Seedless') were obtained from a local orchard and were used on the day of harvest. Before treatments, fruit were thoroughly washed with water and then air dried. Experiments were repeated two to four times, with 140 fruit replications for each postharvest treatment and six fruit per treatment for the artificial inoculation experiments. $P$. digitatum was obtained from an infected grapefruit and cultured on Potato Dextrose Agar (Difco, Detroit, Mich.). Spore suspensions were prepared by removing the spores with a bacteriological loop from the sporulating edges of a 2- or 3-week-old culture, and suspending them in sterile distilled 

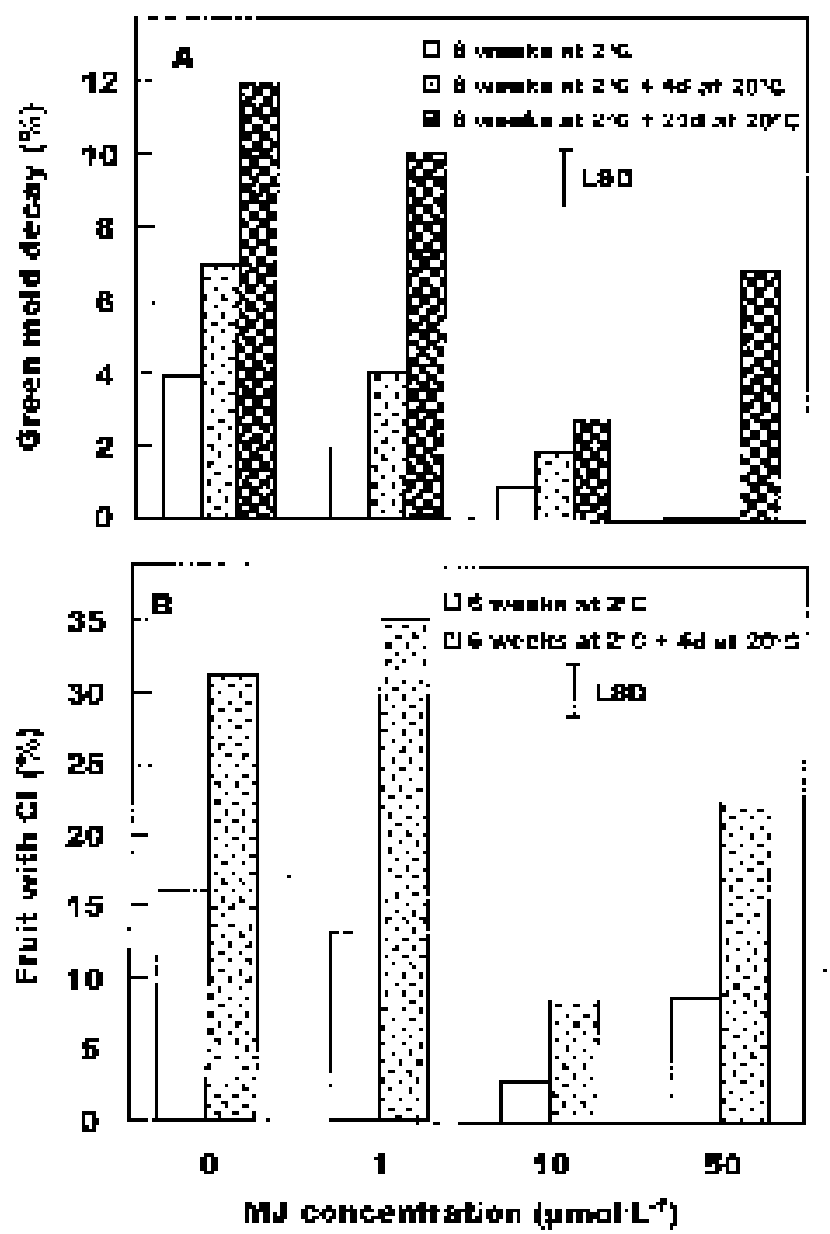

Fig. 1. Effect of methyl jasmonate (MJ) on the incidence of postharvest decay (A) and on the percentage of grapefruit with chilling injury (CI) (B) after 6 weeks of low-temperature storage and simulated shelf life. Fruit were dipped for $30 \mathrm{~s}$ in water or various concentrations of MJ, and then stored at $2{ }^{\circ} \mathrm{C}$ for 6 weeks. Decay and CI were evaluated immediately after storage and after $4 \mathrm{~d}$ of simulated shelf life at $20^{\circ} \mathrm{C}$. Decay was also evaluated after $21 \mathrm{~d}$ of shelf life. Fruit with CI were defined as fruit with moderate to severe CI symptoms. Data are means of 140 fruit per treatment in three different experiments. An overall LSD at $P \leq 0.05$ is shown for means comparison.

water. The spore concentration was determined with a hemocytometer and adjusted as required.

Preparation of Jasmonates. JA (Sigma) and MJ (Aldrich Chemical Co. Inc., Milwaukee, Wis.) were each prepared as a 100 $\mathrm{mmol} \cdot \mathrm{L}^{-1}$ stock solution in $2 \mathrm{~mol} \cdot \mathrm{L}^{-1}$ ethanol plus $500 \mathrm{mg} \cdot \mathrm{L}^{-1}$ of the surfactant L-77 (dimethyl polysiloxane modified with alkylene oxide) (Union Carbide Co., N.Y.). Jasmonates were then adjusted to their final concentrations for application by diluting in distilled water.

Postharvest MJ treatment and Storage. For postharvest treatments, fruit were dipped for $30 \mathrm{~s}$ in various concentrations (1 to $50 \mu \mathrm{mol} \cdot \mathrm{L}^{-1}$ ) of $\mathrm{MJ}$, and then air dried in the shade. Control fruit were similarly dipped in water containing $500 \mathrm{mg} \cdot \mathrm{L}^{-1}$ of L-77. The treated fruit were stored at $2{ }^{\circ} \mathrm{C}$ for 6 weeks, and subsequently transferred to $20^{\circ} \mathrm{C}$ for 3 additional weeks; the relative humidity was $90 \%$ in both storage temperatures.

Evaluation OF DECAY AND CHILling InJURY. Evaluation of decay incidence was performed at the end of the 6-week cold storage, and after 4 and $21 \mathrm{~d}$ of subsequent shelf life at $20^{\circ} \mathrm{C}$. The total number of fruit manifesting decay symptoms (mainly green mold) was determined in each treatment and expressed as the decay percentage. Evaluation of CI was performed at the end of the 6 -week cold storage and after an additional $4 \mathrm{~d}$ at $20^{\circ} \mathrm{C}$. Grapefruit $\mathrm{CI}$ symptoms were manifested as rusty surface pitting. The severity of CI symptoms was assessed visually according to a four-stage scale, as follows: $1=$ no pitting; $2=$ a few scattered pits; $3=$ pitting covering up to $30 \%$ of the fruit surface; and $4=$ extensive pitting covering $>30 \%$ of the fruit surface. The CI index was calculated according to the severity of symptoms (S) and the number of fruit affected (N) \{Eq. [1]\}.

$$
\left[\frac{\sum_{i=1}^{4}\left(\mathrm{~N}_{\mathrm{i}} \times \mathrm{S}_{\mathrm{i}}\right)}{\sum_{\mathrm{i}=1}^{4} \mathrm{~N}_{\mathrm{i}}}\right] \text { ? }
$$

The percentage of injured fruit was defined as the percentage of grapefruit with moderate to severe CI index (stages 3 and 4); such fruit were considered as unacceptable for sale and consumption.

IN VIVO ASSAYS WITH WOUNDED GRAPEFRUIT. Grapefruit rinsed under tap water were dried and wounded with a desiccating needle (1 to $2 \mathrm{~mm}$ deep) at three sites around the stem end, and aliquots of $25 \mu \mathrm{L}$ of jasmonate solutions were pipetted into each wound. Wounds of control fruit were treated similarly with sterile-distilled water instead of jasmonates. Wounded sites were inoculated with $25 \mu \mathrm{L}$ of spore suspension of $P$. digitatum $\left(5 \times 10^{4}\right.$ spores $\left./ \mathrm{mL}\right)$ after $24 \mathrm{~h}$ incubation at $24^{\circ} \mathrm{C}$. When dry, grapefruit were kept at $24^{\circ} \mathrm{C}$ in plastic trays under humid conditions for 4 to $7 \mathrm{~d}$ before determining the percent of infected sites. Six fruit were used per treatment (total of 18 wounds), and each experiment was performed four times with JA and twice with MJ.

EFFECT OF JASMONATES ON $P$. digitatum IN Vitro. Spores of $P$. digitatum were suspended in $100 \mathrm{~g} \cdot \mathrm{L}^{-1}$ potato dextrose broth (Difco, Detroit, Mich.) at a final concentration of $2 \times 10^{4}$ spores/ $\mathrm{mL}$. Aliquots $(450 \mu \mathrm{L})$ of spore suspensions were transferred to wells of tissue culture clusters (Corning Costar Corporation, Cambridge, Mass.), and 50- $\mu \mathrm{L}$ aliquots of the various jasmonate solutions were added to give final concentrations of 1 to 1000 $\mu \mathrm{mol} \cdot \mathrm{L}^{-1}$. Samples of the various test solutions $(30-\mu \mathrm{L}$ drops $)$, were placed on ethanol-washed microscope slides (three drops per slide) kept in petri dishes padded with moistened filter paper, and incubated for $24 \mathrm{~h}$ at $25{ }^{\circ} \mathrm{C}$ in darkness. Spore germination and germ tube elongation were measured in three microscope fields, each containing 40 to 50 spores, under a light microscope.

Statistical Analysis. Results were analyzed with the SigmaStat statistical software (Jandel Scientific Software, San Rafael, Calif.). Two-factor analysis of variance (ANOVA) and StudentNewman-Keuls multiple range tests were performed where indicated. Unless noted otherwise, only results significant at $P \leq 0.05$ are discussed.

\section{Results}

EFFECT OF POSTHARVEST DIP TREATMENTS WITH MJ. To eXamine the efficacy of MJ as a potential postharvest treatment to reduce decay in citrus fruit, we dipped grapefruit in MJ solutions of various concentrations ( 1 to $50 \mu \mathrm{mol} \cdot \mathrm{L}^{-1}$ ) and evaluated decay development and CI symptoms after 6 weeks of storage at $2{ }^{\circ} \mathrm{C}$ and 4 and $21 \mathrm{~d}$ of simulated shelf life at $20^{\circ} \mathrm{C}$. The results show that MJ appeared to reduce green mold decay that developed naturally immediately after cold storage and after $4 \mathrm{~d}$ of shelf life in a dosedependent manner (Fig. 1A). However, after the prolonged simulation of shelf life (21 d), dipping in the highest concentration of MJ $\left(50 \mu \mathrm{mol} \cdot \mathrm{L}^{-1}\right)$ appeared to be less effective than dipping in 10 $\mu \mathrm{mol} \cdot \mathrm{L}^{-1} \mathrm{MJ}$ (Fig. 1A). In fruit treated with $10 \mu \mathrm{mol} \cdot \mathrm{L}^{-1} \mathrm{MJ}$, the 
Table 1. Summary of statistical analysis of the effects of methyl jasmonate (MJ) concentration and shelf time at $20^{\circ} \mathrm{C}$ on decay development and chilling injury $(\mathrm{CI})$ in grapefruit after 6 weeks of storage at $2{ }^{\circ} \mathrm{C}$. Mean values were derived from the data of Fig. 1.

\begin{tabular}{lccc}
\hline \hline & $\begin{array}{c}\text { Decay } \\
(\%)\end{array}$ & $\begin{array}{c}\mathrm{CI} \text { index } \\
(1-4)\end{array}$ & $\begin{array}{c}\text { Fruit } \\
\text { with CI } \\
(\%)\end{array}$ \\
Analysis & & & \\
\hline MJ concn $\left(\mu \mathrm{mol} \cdot \mathrm{L}^{-1}\right)$ & $7.6 \mathrm{a}^{\mathrm{z}}$ & $1.77 \mathrm{a}$ & $23.8 \mathrm{a}$ \\
$\quad 0($ control $)$ & $5.4 \mathrm{~b}$ & $1.92 \mathrm{a}$ & $24.2 \mathrm{a}$ \\
1 & $1.9 \mathrm{c}$ & $1.37 \mathrm{~b}$ & $5.7 \mathrm{c}$ \\
10 & $2.3 \mathrm{c}$ & $1.87 \mathrm{a}$ & $15.7 \mathrm{~b}$ \\
50 & & & \\
Time at $20^{\circ} \mathrm{C}(\mathrm{d})$ & $1.7 \mathrm{~b}$ & $1.56 \mathrm{~b}$ & $10.2 \mathrm{~b}$ \\
0 & $3.2 \mathrm{~b}$ & $1.91 \mathrm{a}$ & $24.5 \mathrm{a}$ \\
4 & $8.0 \mathrm{a}$ & $\mathrm{ND}$ & $\mathrm{ND}$ \\
21 & & & \\
Two-factor analysis of variance & $* * *$ & $* * *$ & $* * *$ \\
$\mathrm{MJ}$ concn $(\mathrm{C})$ & $* * *$ & $* * *$ & $* * *$ \\
Time at $20^{\circ} \mathrm{C}(\mathrm{T})$ & $\mathrm{NS}$ & $* *$ & $\mathrm{NS}$ \\
$\mathrm{C} \times \mathrm{T}$ & & &
\end{tabular}

$\overline{{ }^{\mathrm{z}} \text { Means within each column, followed by different letters are significantly }}$ different at $P=0.05$ according to the Student-Newman-Keuls multiple range test.

$\mathrm{y}_{\mathrm{ND}}=$ not determined

NS, ${ }^{* *},{ }^{* * *}$ Nonsignificant or significant at $P=0.01$ or 0.001 , respectively.

incidences of decay during cold storage $\left(2{ }^{\circ} \mathrm{C}\right)$ and after 4 or $21 \mathrm{~d}$ of shelf life were only $0.9 \%, 1.9 \%$, and $2.8 \%$, respectively, compared with $4 \%, 7 \%$, and $12 \%$ in untreated control fruit.

The statistical analysis, summarized in Table 1, indicated that this $10-\mu \mathrm{mol} \cdot \mathrm{L}^{-1} \mathrm{MJ}$ dose was also the most effective concentration in protecting grapefruit against $\mathrm{CI}$ (expressed as percentage of pitted fruit) after cold storage and $4 \mathrm{~d}$ of shelf life (Fig. 1B). In this treatment, the percentage of fruit exhibiting CI during cold storage was only $3 \%$, compared with $16 \%$ in the untreated control fruit. After $4 \mathrm{~d}$ of shelf life, the incidence of CI in $10 \mu \mathrm{mol} \cdot \mathrm{L}^{-1} \mathrm{MJ}$-treated fruit was $8.4 \%$, compared with $31 \%$ in control fruit (Fig. 1B). The severity of CI, expressed as CI index, was also similarly reduced by $10 \mu \mathrm{mol} \cdot \mathrm{L}^{-1} \mathrm{MJ}$ (Table 1 ), as previously reported (Meir et al., 1996). The statistical analysis (Table 1) shows that MJ may affect decay during cold storage in a different manner from the way it affects $\mathrm{CI}$ incidence. However, depending on the shelf-life duration, $10 \mu \mathrm{mol} \cdot \mathrm{L}^{-1} \mathrm{MJ}$ seems to be the most effective concentration to reduce both parameters.

EFFECT OF JASMONATES ON ARTIFICIALLY INOCULATED FRUIT. TO examine the possible effect of jasmonates on decay caused by artificial inoculation with the green mold, $P$. digitatum, in the absence of $\mathrm{CI}$, we pretreated the fruit with several exponential concentrations of jasmonates applied through wounds, and monitored decay development at $24{ }^{\circ} \mathrm{C}$ after inoculation with the fungus. The results (Fig. 2) show that JA effectively reduced the amount of green mold decay that developed in the inoculated wounds in a concentration-dependent manner, with a peak of efficacy at $10 \mu \mathrm{mol} \cdot \mathrm{L}^{-1}$. Thus, at $10 \mu \mathrm{mol} \cdot \mathrm{L}^{-1}, \mathrm{JA}$ reduced decay to $47 \%$ of the amount that developed in nontreated control fruit, whereas 1 and $100 \mu \mathrm{mol} \cdot \mathrm{L}^{-1} \mathrm{JA}$ reduced decay to only $59 \%$ and $78 \%$, respectively. Higher or lower concentrations $(0.1$ or 1000 $\mu \mathrm{mol} \cdot \mathrm{L}^{-1} \mathrm{JA}$ ) were completely ineffective in reducing decay (Fig. 2). Similar results of reduction of green mold rot after artificial inoculation of 'Marsh Seedless' grapefruit with $P$. digitatum were also obtained when MJ instead of JA was applied in the same concentration range (data not shown).
EFFECT OF JASMONATES ON $\boldsymbol{P}$. digitatum IN vitro. To examine whether the effects of JA and MJ in reducing decay caused by the green mold, $P$. digitatum, were due to their direct antifungal activity, we incubated a $P$. digitatum spore suspension in a growth medium containing various concentrations of jasmonates. We found that neither JA nor MJ, at all concentrations tested ( 1 to 1000 $\left.\mu \mathrm{mol} \cdot \mathrm{L}^{-1}\right)$, had any inhibitory effect on $P$. digitatum spore germination and germ tube elongation (data not shown). Moreover, the high concentrations of JA or MJ even enhanced slightly germ tube elongation of the pathogen.

\section{Discussion}

Jasmonates are naturally occurring plant growth regulators, known to be involved in various aspects of plant development and responses to biotic and abiotic stresses (Creelman and Mullet, 1995, 1997). In the present study, we found that postharvest application of jasmonates reduced decay caused by the green mold, P. digitatum, after either natural (Fig. 1A) or artificial (Fig. 2) inoculation of 'Marsh Seedless' grapefruit.

There are only a few reports of exogenously applied jasmonates actually protecting plants against disease development: in potato (Solanum tuberosum L. 'Alpha') and tomato (Lycopersicon esculentum Mill. 'Baby') plants, jasmonates protected against Phytophthora infestans (Cohen et al., 1993); in barley (Hordeum vulgare L. 'Golden Promise') plants JA protected against Erysiphe graminis (Schweizer et al., 1993); in cut roses (Rosa hybrida L. 'Mercedes') and strawberries (Fragaria Xananassa Duch. 'Delmarvel') MJ protected against Botrytis cinerea (Meir et al., 1998; Moline et al., 1997); and in fresh-cut celery (Apium graveolens L.) and peppers (Capsicum annum) MJ reduced microbial contamination (Buta and Moline, 1998).

In a similar manner to our findings in grapefruit (Figs. 1A and 2), $10 \mu \mathrm{mol} \cdot \mathrm{L}^{-1} \mathrm{JA}$ or $\mathrm{MJ}$ was the most effective concentration in reducing decay also in strawberries (Moline et al., 1997) and in fresh-cut celery and peppers (Buta and Moline, 1998). However,

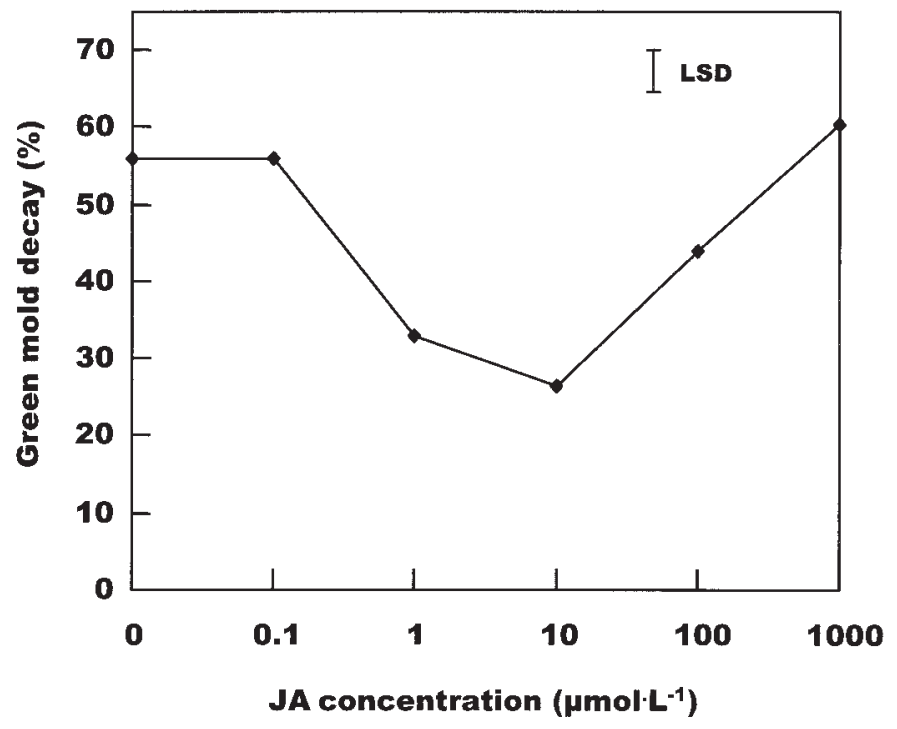

Fig. 2. Effect of exponential concentrations of jasmonic acid (JA) on green mold decay development after artificial inoculation of grapefruit with Penicillium digitatum. Surface wounds were treated with $25 \mu \mathrm{L}$ of various concentrations of $\mathrm{JA}$, and then inoculated with $25 \mu \mathrm{L}$ of a spore suspension of $P$. digitatum $\left(5 \times 10^{4}\right.$ spores $/ \mathrm{mL}$ ). Decay was evaluated after incubation for $4 \mathrm{~d}$ at $24^{\circ} \mathrm{C}$. Data represent means of 72 wounds from 4 different experiments. An overall LSD at $P \leq 0.05$ is shown for means comparison. 
in the other plant systems examined, much higher jasmonate concentrations were required. For example, the most effective concentrations for reducing decay were $200 \mu \mathrm{mol} \cdot \mathrm{L}^{-1} \mathrm{MJ}$ in cut roses (Meir et al., 1998), $300 \mu \mathrm{mol} \cdot \mathrm{L}^{-1}$ jasmonates in potato and tomato plants (Cohen et al., 1993), and $4.8 \mathrm{mmol} \cdot \mathrm{L}^{-1} \mathrm{JA}$ in barley plants (Schweizer et al., 1993). Similar to our present findings in grapefruit (Figs. 1A and 2), MJ is most effective in cut roses in reducing decay when applied in the pulsing solution at an optimal concentration $\left(200 \mu \mathrm{mol} \cdot \mathrm{L}^{-1}\right)$, but is less effective at either higher or lower concentrations (Meir et al., 1998).

We have demonstrated previously that postharvest application of MJ could significantly reduce CI after cold storage of various chilling-susceptible fruit, such as avocado (Persea americana Mill. 'Hass'), grapefruit and bell pepper (Meir et al., 1996). A similar MJ protection against CI was reported previously for zucchini squash (Cucurbita pepo L.) also (Wang and Buta, 1994). The results of the present study further confirm that $10 \mu \mathrm{mol} \cdot \mathrm{L}^{-1}$ MJ was the optimal concentration for reducing $\mathrm{CI}$ in grapefruit after 6 weeks of cold storage and 4 additional d of shelf life (Fig. $1 \mathrm{~B}$, Table 1). It is well known that low-temperature stresses render the commodity to become more susceptible to postharvest pathogens (Bramlage and Meir, 1990). Indeed, storage of grapefruit at temperatures lower than $11^{\circ} \mathrm{C}$ has resulted in CI, expressed as peel pitting of the fruit, increased attack by mold pathogens and stem end rots (Chalutz et al., 1981). In addition, the present statistical analysis clearly shows that the effects of MJ on CI and decay development depend on concentration and duration of the shelf life (Table 1). Therefore, it could be speculated that the inhibitory effect of MJ on the decay of cold-stored fruit (Fig. 1A) may be a result of its inhibitory effect on CI (Fig. 1B), which enhances fruit susceptibility to fungal attack. However, our findings strongly suggest that this is not the case. Firstly, there was no strict correlation between the MJ dose dependency of the two processes: $50 \mu \mathrm{mol} \cdot \mathrm{L}^{-1} \mathrm{MJ}$, which was the most effective concentration for decay reduction after 6 weeks of cold storage and $4 \mathrm{~d}$ of shelf life, was much less effective for CI reduction during this period (Fig. 1 and Table 1$)$. On the other hand, $10 \mu \mathrm{mol} \cdot \mathrm{L}^{-1} \mathrm{MJ}$ was the optimal concentration for decay reduction after $21 \mathrm{~d}$ of shelf life (Fig. 1A). At this time, CI could not be evaluated because of the high percentage of decayed fruit, and because the sporulated funges has completely covered the fruit surface. Secondly, this $10 \mu \mathrm{mol} \cdot \mathrm{L}^{-1}$ MJ (or JA) concentration was also the most effective dose to protect grapefruit against decay caused by artificial inoculation with P. digitatum at $24^{\circ} \mathrm{C}$ (Fig. 2). It appears therefore, that this dose of jasmonates is the optimal one to induce fruit resistance against decay in general, regardless of storage temperature.

MJ dipping of grapefruit seems to provide systemic protection against the green mold rot, $P$. digitatum, by eliciting resistance responses in the treated fruit. This conclusion is based on the following findings of the present study. a) Postharvest application of $\mathrm{MJ}$ to grapefruit significantly reduced the natural development of green mold decay during cold storage and subsequent shelf life at $20{ }^{\circ} \mathrm{C}$ (Fig. 1A, Table 1). b) The optimal dipping dose of MJ obtained for rot inhibition in these fruit was $10 \mu \mathrm{mol} \cdot \mathrm{L}^{-1}$ (Fig $1 \mathrm{~A}$ and Table 1). c) This $10 \mu \mathrm{mol} \cdot \mathrm{L}^{-1} \mathrm{MJ}$ (or JA) concentration was also the optimal effective dose in reducing disease incidence after artificial inoculation of grapefruit with $P$. digitatum at $24^{\circ} \mathrm{C}$ (Fig. 2 ). and d) Jasmonates had no inhibitory effect on $P$. digitatum in vitro, even at high concentrations. It appears therefore, that the effects of jasmonates in reducing decay development in grapefruit were indirect, and operated through enhancement of the fruit natural defenses.

Indeed, in the literature, it is well established that jasmonates induce disease resistance and related responses in a wide variety of plants and cell cultures (Andresen et al., 1992; Chaudhry et al., 1994; Creelman et al., 1992; Creelman and Mullet, 1997; Doares et al., 1995; Farmer and Ryan, 1990; Gundlach et al., 1992; Nojiri et al., 1996; Xu et al., 1994). However, the mode of action of jasmonates in reducing disease development seems to differ among the various plants and pathogens examined. As in grapefruit, jasmonates reduce Phytophthora infestans in tomato and potato plants at much lower concentrations $\left(300 \mu \mathrm{mol} \cdot \mathrm{L}^{-1}\right)$ than those required $\left(3.5\right.$ to $5 \mathrm{mmol} \cdot \mathrm{L}^{-1}$ ) for direct inhibition of the fungus (Cohen et al., 1993), and it was, therefore, suggested that jasmonates might protect the plants through the induction of host resistance responses (Cohen et al., 1993). In barley plants, however, JA reduces Erysiphe graminis only at high concentrations that inhibit appressoria formation and therefore, probably directly inhibit the fungus growth (Schweizer et al., 1993). On the other hand, in cut roses we previously showed that low MJ concentrations (200 $\mu \mathrm{mol} \cdot \mathrm{L}^{-1}$ ) provide systemic protection against Botrytis cinerea by enhancing petal resistance, whereas $400 \mu \mathrm{mol} \cdot \mathrm{L}^{-1} \mathrm{MJ}$ completely inhibits spore germination and germ-tube elongation of the fungus in vitro (Meir et al., 1998). Overall, it seems that the effects and mode of action of jasmonates in reducing disease development differ among the various crops and pathogens examined.

Another possible explanation for the mode of action of jasmonates in inducing disease resistance, may be by their induction of ethylene synthesis (Porat et al., 1993; Saniewski and Czapski, 1985). Especially, since it is known that ethylene induces the resistance of citrus fruit to $P$. digitatum (El-Kazzaz et al., 1983). However, there are also other cases in which jasmonates inhibit ethylene production (Nojavan-Asghari and Ishizawa, 1998). In cut roses, we found that jasmonate-induced resistance to pathogens is not ethylene mediated, since the MJ treatment was assayed in the presence of an ethylene antagonist (Meir et al., 1998). The possible effects of jasmonates on ethylene production in grapefruit were not evaluated in the current study.

In summary, our results clearly suggest that, when applied at low concentrations, jasmonates are potential postharvest treatments to enhance natural resistance and to reduce decay and CI in grapefruit. Since they are naturally occurring compounds and are given in low doses, jasmonates may provide a more environmentally friendly means to reduce the current massive use of chemical fungicides to control postharvest decay of grapefruit.

\section{Literature Cited}

Andresen, I., W. Becker, K. Schluter, J. Burges, B. Parthier, and K. Apel. 1992. The identification of leaf thionin as one of the main jasmonateinduced proteins in barley (Hordeum vulgare). Plant Mol. Biol. 19:193204.

Bramlage, W.J. and S. Meir. 1990. Chilling injury of crops of temperate origin, p. 37-49. In: C.Y. Wang (ed.). Chilling injury of horticultural crops. CRC Press Inc., Boca Raton, Fla.

Buta, J.G. and H.E. Moline. 1998. Methyl jasmonate extends shelf life and reduces microbial contamination of fresh-cut celery and peppers. J. Agr. Food Chem. 46:1253-1256.

Chalutz, E., Y. Waks, and M. Schiffman-Nadel. 1981. The different responses of several citrus fruit cultivars to low temperatures. Proc. Intl. Soc. Citricult. 2:773-774.

Chaudhry, B., F. Muller-Uri, V. Cameron-Mills, S. Gough, D. Simpson, K. Skriver, and J. Mundy. 1994. The barley $60 \mathrm{kDa}$ jasmonate-induced protein (JIP60) is a novel ribosome-inactivating protein. Plant J. 6:815824.

Cohen, E. 1988. Commercial use of long term storage of lemon with intermittent warming. HortScience 23:400-403.

Cohen, Y., U. Gisi, and T. Niderman. 1993. Local and systemic protection 
against Phytophthora infestans induced in potato and tomato plants by jasmonic acid and jasmonic methyl ester. Phytopathology 83:1054 1062.

Creelman, R.A. and J.E. Mullet. 1995. Jasmonic acid distribution and action in plants: Regulation during development and responses to biotic and abiotic stress. Proc. Natl. Acad. Sci. USA 92:4114-4119.

Creelman, R.A. and J.E. Mullet. 1997. Biosynthesis and action of jasmonates in plants. Annu. Rev. Plant Physiol. Plant Mol. Biol. 48:355381

Creelman, R.A., M.L. Tierney, and J.E. Mullet. 1992. Jasmonic acid/ methyl jasmonate accumulate in wounded soybean hypocotyls and modulate gene expression. Proc. Natl. Acad. Sci. USA 89:4938-4941.

Doares, S.H., T. Syrovets, E.W. Weiler, and C.A. Ryan. 1995. Oligogalacturonides and chitosan activate plant defense genes through the octadecanoid pathway. Proc. Natl. Acad. Sci. USA 92:4095-4098.

Eckert, J.W. and G.E. Brown. 1986. Postharvest citrus diseases and their control, p. 315-360. In: W.F. Wardowski, S. Nagy, and W. Grierson (eds.). Fresh citrus fruits. AVI Publishing Co. Inc., Westport, Conn.

Eckert, J.W. and J.M. Ogawa. 1985. The chemical control of postharvest diseases: subtropical and tropical fruits. Annu. Rev. Phytopathol. 23:421454.

El-Kazzaz, M.K., A. Chordas, and A.A. Kader. 1983. Physiological and compositional changes in orange fruit in relation to modification of their suspectibility to Penicillium digitatum by ethylene treatments. J. Amer. Soc. Hort. Sci. 108:618-621.

Farmer, E.E. and C.A. Ryan. 1990. Interplant communication: Airborne methyl jasmonate induces synthesis of proteinase inhibitors in plant leaves. Proc. Natl. Acad. Sci. USA 87:7713-7716.

Gundlach, H., M.J. Muller, T.M. Kutchan, and M.H.Zenk. 1992. Jasmonic acid is a signal transducer in elicitor-induced plant cell cultures. Proc. Natl. Acad. Sci. USA 89:2389-2393.

Meir, S., S. Philosoph-Hadas, S. Lurie, S. Droby, M. Akerman, G. Zauberman, B. Shapiro, E. Cohen, and Y. Fuchs. 1996. Reduction of chilling injury in stored avocado, grapefruit, and bell pepper by methyl jasmonate. Can. J. Bot. 74:870-874.

Meir, S., S. Droby, H. Davidson, S. Alsevia, L. Cohen, B. Horev, and S. Philosoph-Hadas. 1998. Suppression of Botrytis rot in cut rose flowers by postharvest application of methyl jasmonate. Postharvest Biol. Tech- nol. 13:235-243.

Moline, H.E., J.G. Buta, R.A. Saftner, and J.L. Maas. 1997. Comparison of three volatile natural products for the reduction of postharvest decay in strawberries. Adv. Strawberry Res. 16:43-48.

Nojavan-Asgjari, M. and K. Ishizawa. 1998. Inhibitory effects of methyl jasmonate on germination and ethylene production in cocklebur seeds. J. Plant Growth Regul. 17:13-18.

Nojiri, H., M. Sugimori, H. Yamane, Y. Nishimura, A. Yamada, N. Shibuya, O. Kodama, N. Murofushi, and T. Omori. 1996. Involvement of jasmonic acid in elicitor-induced phytoalexin production in suspension-cultured rice cells. Plant Physiol. 110:387-392.

Porat, R., A. Borochov, and A.H. Halevy. 1993. Enhancement of petunia and dendrobium flower senescence by jasmonic acid methyl ester is via the promotion of ethylene production. Plant Growth Regul. 13:297-301.

Rodov, V., S. Ben-Yehoshua, R. Albagli, and D.Q. Fang. 1995. Reducing chilling injury and decay of stored citrus fruit by hot water dips. Postharvest Biol. Technol. 5:119-127.

Saniewski, M. and J. Czapski. 1985. Stimulatory effect of methyl jasmonate on the ethylene production in tomato fruits. Experientia 41:256257.

Schiffmann-Nadel, M., E. Chalutz, J. Waks, and M. Dagan. 1975. Reduction of chilling injury in grapefruit by thiabendazole and benomyl during long term storage. J. Amer. Soc. Hort. Sci. 100:270-272.

Schweizer P., R. Gees, and E. Mosinger. 1993. Effect of jasmonic acid on the interaction of barley (Hordeum vulgare L.) with the powdery mildew Erysiphe graminis f.sp. hordei. Plant Physiol. 102:503-511.

Sembdner, G. and B. Parthier. 1993. The biochemistry and the physiological and molecular actions of jasmonates. Annu. Rev. Plant. Physiol. Plant Mol. Biol. 44:569-589.

Wang, C.Y. 1993. Approaches to reduce chilling injury of fruits and vegetables. Hort. Rev. 15:83-95.

Wang, C.Y. and J.G. Buta. 1994. Methyl jasmonate reduces chilling injury in Cucurbita pepo through its regulation of abscisic acid and polyamine levels. Environ. Expt. Bot. 34:427-432.

Xu, Y., P.L. Chang, D. Liu, M.L. Narasimhan, K.G. Raghothama, P.M. Hasegawa, and R.A. Bressan. 1994. Plant defense genes are synergistically induced by ethylene and methyl jasmonate. Plant Cell 6:10771085 . 